\title{
Ensino de geografia para surdos: uma questão de língua e linguagem
}

\author{
Geography education for deaf people: a matter of language
}

\author{
Camilo Darsie \\ Douglas Luís Weber \\ Daniel Felipe Schroeder \\ Juliana Vanesi Lopes da Silva \\ Universidade de Santa Cruz do Sul - Unisc - Santa Cruz do Sul - Rio Grande do Sul - Brasil \\ $\longrightarrow$
}

Resumo: Muitas discussões e desafios que envolvem o ensino para surdos vêm sendo realizadas no campo das licenciaturas e, consequentemente, na Geografia. Para os professores que trabalham nesta área, a Língua de Sinais Brasileira (Libras) é fundamental para o despertar de ideias, de questionamentos, de reflexões e de transformações junto aos alunos surdos. A partir disso, o texto aborda a relevância do conhecimento e da utilização da Libras e dos sinais específicos da Geografia no contexto do ensino de surdos, tendo em vista os deslocamentos ocorridos, também, na Geografia escolar. O tema é relevante diante dos debates, das políticas públicas e dos direitos relacionados aos campos da Educação Especial, da Educação de Surdos e da Educação Inclusiva que se tornam cada vez mais visíveis em nossa sociedade. Assim, a partir de levantamento bibliográfico, apresentamos uma reflexão relativa à importância de conhecimentos relacionados à Libras para o ensino de Geografia para surdos. Nosso objetivo tem a ver com o tensionamento de didáticas, especialmente, na Geografia enquanto matéria escolar. Diante disto, observamos que é necessário investimento, por parte de profissionais, no sentido de compreenderem que a Libras e seus sinais específicos geográficos são fundamentais para um ensino de Geografia que prioriza a visão crítica do espaço.

Palavras-chave: Ensino, Língua Brasileira de Sinais; Geografia.

Abstract: Many discussions and challenges involving the education for the deaf students. That have been carried out in the education area and, consequently, in Geography. For teachers who working in this area, the Brazilian Sign Language (Libras) is the key of to the awakening of ideas, questions, reflections and transformations for the deaf students. From this, the text discusses the relevance of knowledge and use of the Libras and specific signs of Geography in the context of deaf education in view of the displacements occurred also in the school. The theme is relevant before the debates, public policy and rights related to the fields of Special Education, Deaf Education and Inclusive Education that become increasingly visible in our society. Thus, from literature review, we present a reflection about the importance of Libras knowledge related to the teaching of Geography for the deaf. Our goal has to do with the tension of teaching, especially in Geography. In view of this, we note that it is necessary investment by professionals, to understand that Libras and geographical specific signals are essential for a teaching geography that prioritizes critical view of space.

Keywords: Education; Brazilian Sign Language; Geography. 


\section{Introdução}

Ministrar aulas de Geografia para surdos é um grande desafio, pois, assim como em outras disciplinas escolares, é necessário que sejam pensadas e desenvolvidas estratégias didáticas por meio da Língua Brasileira de Sinais (Libras). Esta situação deixa muitos professores aflitos, especialmente pelo fato de grande parte dos profissionais não conhecer ou não dominar a Libras, ou seja, a língua adequada para que alunos surdos possam alcançar maiores níveis de conhecimento e potencial crítico e reflexivo. No entanto, cada vez mais, a necessidade de aperfeiçoamento acerca deste tema, no contexto educativo, é fundamental em função do aumento de debates, de políticas públicas e de direitos relacionadas aos campos da Educação Especial, da Educação de Surdos e da Educação Inclusiva.

Nesta direção, ainda é possível pensarmos que, mesmo em casos em que as aulas são ministradas por professores que conhecem a língua, há lacunas no que se refere ao vocabulário específico relativo às diferentes disciplinas, entre elas a Geografia. Tal realidade é potencializada pela falta de padronização - por meio de documentos oficiais, como dicionários - ou do conhecimento de vocábulos relativos aos conceitos que envolvem a matéria. Assim, em muitos casos, dinâmicas que privilegiem o pensamento crítico e/ou reflexivo acerca de questões geográficas são substituídas por práticas que envolvem a repetição e memorização de assuntos diversos. No que diz respeito à Geografia - e a qualquer outra matéria escolar - esta situação é preocupante e precisa ser atentada.

Considerando tal questão, apresentamos uma discussão que articula questões relativas ao ensino de Geografia à Libras. É importante destacarmos, antes de avançarmos, que não buscamos apresentar uma proposta didática que proponha a solucionar os desafios mencionados, mas provocar reflexões acerca da prática docente relacionada ao ensino de Geografia para surdos.
Para tanto, o texto está dividido em três seções. $\mathrm{Na}$ primeira, apresentamos elementos referentes aos deslocamentos pelos quais o ensino de Geografia vem passando no decorrer dos anos e, na sequência, questões acerca da Libras e da importância dela no processo ensino-aprendizagem de Geografia para surdos. Por último, apresentamos as considerações finais.

\section{Questões sobre o ensino de Geografia}

Em decorrência das transformações culturais, materiais e tecnológicas que acompanham as sociedades, emerge a necessidade de serem feitas análises e reflexões que nos permitam compreender, no limite do possível, as dinâmicas que lhes envolvem e as que, consequentemente, são produzidas por elas. Assim, a complexidade do mundo e das relações que se estabelecem entre diferentes elementos, naturais e sociais, configuram o foco de discussão daqueles que pesquisam, trabalham e/ou estudam a Geografia. Neste sentido, em termos gerais, é possível dizer que a Geografia é uma ciência que estuda questões bastante complexas, pois aborda os fenômenos físicos, biológicos, humanos e, principalmente, as formas pelas quais estes variam, de modo articulado, configurando o espaço, como é chamado no contexto de outros países, ou, mais precisamente, o espaço geográfico, como é chamado no Brasil (DARSIE, 2014; MASSEY, 2009, SANTOS, 1979).

Porém, ao ter sido inserida no currículo escolar, no princípio, a disciplina teve a finalidade de contribuir com a formação dos cidadãos a partir da difusão da concepção do nacionalismo. Sua presença se firmou nas escolas primárias e secundárias da Europa, no século XIX, de acordo com os interesses políticos e econômicos da época, contribuindo com a formação de um perfil de cidadão considerado patriota e nacionalista. Neste contexto, as investidas que envolviam as práticas pedagógicas desta matéria eram direcionadas a descrição do ambiente natural. $O$ objetivo disto era apresentar dados e informações gerais sobre os territórios (países vizinhos, 
continentes e principalmente os territórios em que os estudantes se inseriam), de modo que pudessem ser constituídos sujeitos com uma grande devoção e cordialidade ao seu país (RIBEIRO, 2011).

Segundo Vlach (1988), a Geografia escolar tinha como função:

"Mostrar através de descrições, mapas com contornos do país e da observação direta do meio circundante o próprio Estado-Nação, valorizando-o e criando laços de respeito e dedicação à imagem da pátria, para que, se fosse preciso, se lutasse/guerreasse por ela. Assim, a Geografia oficializou-se nas escolas com o objetivo de formar o futuro patriota/soldado" (p. 2684).

No Brasil, mesmo que em anos posteriores, não foi diferente, já que por volta de 1930, com a grande expansão urbana, com a constituição do mercado nacional e com o constante crescimento industrial houve uma grande exigência de trabalhadores e de mão-de-obra alfabetizada que pudessem dar conta das demandas nacionais. Portanto, o ensino da Geografia começou, assim como no caso de outras matérias, a se difundir entre a população de modo a estabelecer sentimentos de nacionalismo vinculado ao desenvolvimento (VLACH, 1988).

Partindo disto, várias mudanças ocorreram no que se refere à maneira de se praticar o ensino da Geografia. Nas últimas décadas, por exemplo, esta ciência chegou a ser caracterizada como frágil, em função de ser baseada em modelos tradicionais, por meio dos quais o "conhecer" era substituído pelo "decorar". Neste sentido, o ensino da Geografia valorizava o domínio de dados acerca dos aspectos físicos da Terra (dados estatísticos, nome de rios, países, captais, etc.). As transformações econômicas, políticas e sociais que vinham se desenvolvendo no Brasil e no mundo fizeram com que o padrão de ensino aceito, até então, fosse questionado. Vários geógrafos passaram a procurar novos paradigmas para que fossem capazes de explicar e teorizar as constantes transformações ocorridas no espaço (PESSOA, 2007).

Para Pereira (1988, apud PESSOA, 2007):
"Um desses fatores seria a própria incapacidade da Geografia Tradicional de dar conta de uma realidade altamente explosiva produzida pela expansão do sistema capitalista e todas as suas contradições: afloram problemas urbanos, agrários, políticos e a Geografia Tradicional segue no seu velho lenga-lenga de "relevo, clima, vegetação, agricultura, indústria". A realidade não tinha e não tem a ver com a harmonia que essa Geografia, e também a maior parte dos livros didáticos, nos transmite" (p. 59).

Assim, a partir da segunda década do século $X X$, a Geografia começou a transformar-se por meio da contestação ao modelo até então vigente, baseado nas prerrogativas de um ensino tradicional.

Para confrontar a Geografia Tradicional vários geógrafos, pesquisadores e professores propuseram o ensino desta ciência com um novo olhar, crítico, surgido em meados da década de 1970 e baseado em manifestações estudantis ocorridas na França e na luta contra a discriminação racial que se desenrolava nos Estados Unidos da América. Com ideias marxistas, a Geografia Crítica buscou se envolver com novos assuntos, tendo uma grande aproximação com movimentos sociais, passando a lutar por uma sociedade justa e igualitária (BRITO e PESSOA, 2009; MOURA et al., 2008).

Os mais diversos processos de transformação da disciplina, ocorridos, principalmente, após o final da década de 1970, colocaram um novo olhar sobre o ensino e pesquisa de/em Geografia. Mais tarde, este movimento ficou conhecido como Movimento de Renovação ${ }^{1}$ e encaminhou a disciplina para novos discursos e olhares. A partir deste momento, segundo Cavalcanti (2002, p.11), a mudança ocorreu "para se fazer uma análise crítica da fundamentação teóricometodológica da ciência geográfica e para se propor alternativas ao modo de trabalhar essa ciência enquanto matéria escolar". Para ele, a Geografia Tradicional é uma ciência ultrapassada, na qual a

\footnotetext{
${ }^{1}$ O movimento de renovação caracteriza-se por uma passagem da Geografia tradicional para a crítica. A busca de novos caminhos, uma nova linguagem, novas propostas são agora pressupostos para a criação de uma disciplina mais reflexiva e emancipatória (CAVALCANTI, 2002).
} 
única forma de se "entender" o espaço é memorizando informações sobre ele.

Segundo o mesmo autor, para que a Geografia faça sentido, conforme a entendemos atualmente, é necessário fazer com que os alunos criem suas próprias construções acerca do espaço, avaliando, discutindo fatos e acontecimentos originados por diversas dinâmicas.

As propostas de reformulação do ensino de Geografia também têm em comum o fato de explicarem as possibilidades da Geografia e da prática de ensino de cumprirem papéis politicamente voltados aos interesses das classes populares. (...) O ensino de Geografia, assim, não se deve pautar pela descrição e enumeração de dados, priorizando apenas aqueles visíveis e observáveis na sua aparência (...). Ao contrário, o ensino deve priorizar ao aluno a compreensão do espaço geográfico na sua concretude, nas suas contradições (CAVALCANTI, 2005, p.20).

Na mesma direção, Callai (1988) argumenta que a Geografia era uma disciplina de "decorar", de saber os nomes de rios, de cidades, entre outros e não voltada ao entendimento do espaço geográfico. $O$ ensino da Geografia atual, para a autora, frente a tantas mudanças que ocorrem no mundo e às propostas de transformação e reformulação curricular da escola, exige que se pense novas alternativas de ensino, a partir da necessidade de se refletir e de se praticar novos modelos didáticos.

A importância desta ciência e de seu ensino na escola é notada pelo fato de que é a partir de nossa existência e de nossas identidades que se forma o espaço ao mesmo tempo em que esta dimensão é responsável por tais elementos (MASSEY, 2009). Pensar o ser humano é pensar acerca do espaço que habitamos, transformamos e, no limite, que somos. Existir significa fazer/ser Geografia. Se, muitas vezes, como disciplina escolar, a Geografia é taxada como desagradável aos alunos, em outros momentos precisa ser fortalecida enquanto uma prática social pertinente a qualquer grupo humano. Ela está fundamentada em princípios, métodos e técnicas que Ihes são pertinentes e necessárias, entre elas, a criticidade.
Além disto, é organizada em bases teóricofilosóficas que abrangem conceitos peculiares. A Geografia escolar é considerada uma área de conhecimento que envolve a educação em geral, integra conteúdo da ciência geográfica e, também, de outros campos do saber. Isto a torna interdisciplinar. Ensinamos quando ajudamos e estimulamos a aprender e a buscar, a se transformar enquanto cidadão e quando permitimos debates para que os estudantes transformem informações em conhecimentos. Por isso, o que se espera da Geografia escolar é que o aluno possa "ler a paisagem, ler o mundo da vida, ler o espaço construído [...] é isto que se espera da Geografia no mundo atual" (CALLAI, 2003, p. 60-61).

A possibilidade de novos caminhos para a Geografia à levaram na direção de uma grande e profunda mudança no que se refere ao seu campo do ensino. Podemos constatar uma crescente gama de trabalhos científicos, produzidos nos últimos anos, que criticam e apresentam grandes fragilidades de um ensino com base na Geografia Tradicional e que passam a propor uma nova forma de ensinar a Geografia. O objetivo disto é oportunizar aos alunos olhares mais críticos, reflexivos e emancipatórios acerca do espaço e de suas próprias construções de conhecimento (TADIOTTO; BOGADO; SPANCESKI, 2010).

Essa nova forma de entender a Geografia precisa ser pensada como o instrumento que torna os alunos sujeitos efetivos em seus processos de aprendizagem e que, a partir de suas realidades, garante que eles possam transformar seus conhecimentos a ponto de questioná-los. Não é mais cabível que a escola apenas os façam reproduzir conhecimentos preexistentes e moldados.

Os conteúdos da Geografia escolar precisam ser selecionados e organizados pelos professores de modo a estarem adequados à Educação Básica - e todas as modalidades que a envolvem, entre elas a Educação Inclusiva e a Educação de Surdos objetivando desenvolver junto aos alunos as noções de observação, de análise e de pensar criticamente a realidade e o espaço em que vivem. Outro aspecto 
que envolve o ensino da Geografia escolar contempla questões sociais como, por exemplo, a desigualdade social, o desemprego, o fortalecimento das minorias, entre outros. Essas questões são importantes para a formação da cidadania e da participação efetiva dos cidadãos com os quais a escola se envolve. Assim, destacamos que para além dos conteúdos que formam a disciplina, as posturas e engajamentos profissionais passam a ser importantes ferramentas no processo de transformação social.

Segundo Tadiotto, Bogado e Spanceski (2010) o ensino de Geografia deve proporcionar aos alunos uma melhor percepção de suas vivências como sujeitos em uma sociedade, enfatizando suas realidades e possibilitando que a partir delas construam seus conhecimentos e transformem suas vidas. Ainda, é importante lembrar que tal qual como as outras disciplinas básicas, a Geografia possuí uma linguagem própria e os alunos devem dominá-la para organizar uma breve leitura do seu mundo.

Partindo destas questões, destacamos que no caso de alunos surdos, a situação não é diferente. Do mesmo modo que as transformações espaciais mais complexas estabelecem importantes mudanças nos modos de ensinar e organizar as dinâmicas escolares, as atuais demandas relacionadas à atenção às diferenças também impõem desafios a serem vencidos. Assim como no caso das práticas direcionadas a alunos ouvintes, no caso de alunos surdos, a Geografia deve manter seu caráter crítico e reflexivo, por meio da autonomia associada às possibilidades de entender o mundo e as distintas realidades por meio da gama de conceitos que the constituem enquanto ciência e matéria escolar.

Assim, um dos pontos fulcrais é a compreensão de que para que tal objetivo seja alcançado é necessário pensar e fazer o ensino de Geografia, para surdos, por meio da Libras. Portanto, na seção que se segue, abordamos questões relacionadas à este tema.

\section{Língua e Linguagem}

Desde os primórdios da existência humana, devido à grande necessidade de interação entre os participantes de comunidades, a língua passou a ser desenvolvida como uma ferramenta essencial para a sobrevivência. A cada nova palavra, foi-se atribuindo um conjunto de significados e, assim, com o passar dos tempos, ela foi se desenvolvendo e adquirindo particularidades através dos diferentes grupos sociais. Para Quadros e Karnopp (2004), a língua começou a se desenvolver pela necessidade de que os seres humanos tinham de interagir com o outro, a fim de sobreviverem e trabalharem reciprocamente. Surgiu, então, a primeira função da língua: a comunicação.

A língua age como um mecanismo cerebral, em que, através de associações realizadas por estímulos externos, emergem símbolos distintos que são memorizados e reproduzidos pelo intelecto. Cada nova incitação é capaz de ativar milhares de impulsos nervosos na mente cujo resultado pode ser expressado a partir de uma palavra ou até mesmo uma frase em um diálogo. Em referência a essa colocação, Perini (2010) afirma que a língua é definida como um sistema programado em nosso cérebro responsável por criar uma relação entre os esquemas mentais que nos permitem compreender o mundo e o código que os representa de maneira que seja perceptível aos sentidos e a expressão do pensamento.

Nasi (2007) define a língua como uma ferramenta que permite o homem se comunicar e interagir com ideias. Ainda, de acordo com a autora, há muitas dúvidas acerca de uma definição considerada mais correta no que se refere a língua, inclusive sobre o que permite seu entendimento, forma de utilização e até mesmo o porquê de tantas definições para a palavra. Assim, essas questões reforçam a complexidade do tema.

Contudo, a língua é algo universal, estando presente em todas as comunidades e agindo na diferenciação de culturas e determinação de territórios. Não há uma língua superior ou inferior, principalmente em territórios com forte diversidade linguística (TELES, 2005). A língua possibilita 
conhecer o mundo, operando também como suporte para a interação social. Em consequência da inevitabilidade que a comunicação é para o homem, a língua está constantemente modificando-se e desenvolvendo-se em constante articulação com a linguagem.

Aqui, é importante destacarmos que entrelaçado ao conceito de língua, está o de linguagem. Para além de tão somente aprender a se comunicar, os contextos social e cultural em que um sujeito se insere também agregam uma gama de ideias e modos de se relacionar que servirão de guias no seu processo de desenvolvimento linguístico e pessoal. O conhecimento passa a ser construído a partir da linguagem. O conhecimento linguístico, em decorrência disso, também ocorre a partir dessa necessidade em interagir e se comunicar com os demais (SCHULZ et al., 2012).

Buscando melhor esclarecer esses conceitos heterogêneos, porém, complementares Perini (2010) profere que:

"[...] a relação entre língua e linguagem é que uma "língua" é uma das maneiras como se manifesta exteriormente a capacidade humana a que chamamos "linguagem". Mas o termo linguagem é também aplicado a outros tipos de sistemas de comunicação, que normalmente não são chamados línguas, como o sistema de sinais de trânsito e a linguagem das abelhas. Assim, linguagem é um conceito muito mais amplo do que língua: a linguagem inclui as línguas entre suas manifestações, mas não apenas as línguas. (p. 2)

No campo da educação, ela é muito mais do que uma forma de representar através da língua o que se pensa, ela liberta e impulsiona no sentido de se pensar determinadas questões motivando os alunos a participarem das discussões abordadas, atuando como mediadora entre o sujeito e o objeto do conhecimento, tornando-se fundamental para a construção desses conceitos.

Percebendo-se ser a língua um fenômeno de comunicação de ideias, sentimentos, percepções da realidade, emoções, nota que a sua origem decorre de um fato social: a necessidade da comunicação interpessoal. Independente de sua origem ser onomatopéica, como mera repetição dos sons percebidos, nota-se a influência do meio social, e por isso da história, para que houvesse a formação da língua. Já a linguagem pode ser entendida como um estudo, uma reflexão sobre a existência, condições, maneiras e formas de existência das línguas, permitindo um estudo posterior de um fenômeno intrinsicamente humano: a comunicação das consciências (MINUZI 2012).

No caso dos surdos, é importante se saber que a modalidade de língua utilizada por tais sujeitos não é a mesma dos ouvintes. Esta informação é um dos primeiros elementos que devem ser considerados no que se refere ao ensino de Geografia para tais alunos.

Geralmente, profissionais da área da Educação associam as Línguas de Sinais (LS) a uma forma de linguagem por desconhecerem aspectos legais e estruturais destas. Isto acaba oportunizando certa noção de que tais línguas seriam apenas suportes para o alcance de conhecimentos que ajudam a chegar ao domínio "da" língua oficial de cada país.

Contudo, as Línguas de Sinais se diferem das línguas orais pela fonte a qual se expressam, ou seja, utilizam-se de um meio visual não auditivo, pois a comunicação se estabelece através de configurações manuais. Cada país possui sua própria Língua de Sinais, sendo assim, há Línguas de Sinais inglesa, francesa, alemã, italiana e assim por diante.

A Língua de Sinais são sistemas de sinais
independentes das línguas faladas. Não
existe uma língua de sinais utilizada e
compreendida universalmente, diferindo
uma das outras, por exemplo: no Brasil
temos a LIBRAS (Língua Brasileira de
Sinais); nos EUA utiliza-se a ASL
(American Sing Language); e na França a
LSF (Langue de Signes Français).
Existindo como as línguas orais, dialetos
ou variabilidade regional dos sinais. A
língua de sinais é uma língua de dimensão
espacial e corporal. (DEUS, 2012, p.6)

No caso do Brasil, a Libras é uma língua oficializada e definida por meio da lei federal 10.436 de 24 de abril de 2002. Tal situação nos encaminha a pensar que os aspectos legais que envolvem a Libras impactam diretamente as práticas escolares. Mais 
precisamente, no que diz respeito ao ensino de Geografia, isto desafia e desacomoda professores, pois, conforme apontado anteriormente, nesta disciplina, a capacidade de discernimento, reflexão e criticidade se torna fundamental. Aspectos como estes só podem ser garantidos, para os surdos, por meio da utilização da Libras (e linguagens que se associam a esta língua e à Geografia).

Em turmas com alunos surdos, as aulas devem ser ministradas a partir da Libras ou devem haver intérpretes habilitados. Esta ação possibilita ao sujeito surdo se comunicar e interagir com seus grupos de estudo e com a sociedade em geral. Neste contexto, é importante ser dito que, para além das práticas desenvolvidas em sala de aula, ao se fazer uso da Libras fortalece-se a possibilidade da própria língua passar a ser mais difundida e reconhecida como um marcador cultural, brasileiro, legalmente reconhecido que privilegia aspectos relacionados às diferenças $e$ às minorias, ou seja, elementos bastante caros à Geografia contemporânea.

A partir disto, vale a pena se observar as palavras de Araújo et al (2007):

"A língua de sinais possibilitou ao surdo o reconhecimento de sua identidade enquanto sujeito, o qual deixa de ser visto como incapaz e passa a ter direito como cidadão. Ao possuir uma língua, o surdo passou a se comunicar de maneira consciente, tornando-se mais participativo, não apenas na sala de aula, como nas relações sociais". (p. 14).

Ainda, sobre o mesmo aspecto, Rosa (2013) afirma que:

A linguagem é essencial no desenvolvimento de qualquer criança, pois a linguagem é um instrumento de poder e aos surdos não pode ser negado o direito de usufruir dos benefícios de uma língua, portanto, aceitar a diferença do surdo e conviver com a diversidade humana é um desafio proposto à sociedade. A língua de sinais se torna uma ferramenta que permite ao surdo maior mobilidade e fluidez nas formações discursivas, como também fornece subsídios que o ajudam na constituição de suas identidades frente às imposições culturais do ouvinte (p. 7).
Dentro dessa perspectiva, Gesueli (2006), argumenta que a linguagem é um aspecto relevante para a educação de surdos. Para ela, o contato de alunos surdos com outros não ouvintes é fundamental para que a construção do conhecimento se atinja de fato:

Se o tema da linguagem na construção
da identidade deve ser considerado no
processo educacional de qualquer
sujeito, mais significativo ele se torna na
questão da surdez, pois em razão do
uso da língua de sinais a criança surda
filha de pais ouvintes, possivelmente,
terá poucas oportunidades de usar
significativamente essa língua. Em
outras palavras, as possibilidades de
aquisição da língua de sinais estarão
restritas ao contato com a comunidade
surda. (Gesueli, 2006, p. 282.)

Diante disto, ressaltamos que além do contato com outros não ouvintes, a interação com professores que saibam se comunicar por meio da Libras é de extrema importância. Partindo disto, retomamos os argumentos de autores como, por exemplo, Callai (2003), quando infere que o ensino de Geografia deve levar em conta as bases teórico-filosóficas e seus conceitos específicos. Assim, no contexto do ensino de Geografia para surdos, para que consigamos nos deslocar de práticas que se identifiquem com a Geografia Tradicional é necessário que os professores de que trabalham com alunos surdos dominem a Libras, de modo geral, mas, especialmente, invistam no aprofundamento do domínio de linguagem específica da Geografia.

Esta investida é capaz de oportunizar sentido aos conhecimentos geográficos para alunos surdos, pois, retomando Cavalcanti (2005), é necessário se fazer com que os alunos - ouvintes ou surdos - criem suas próprias construções acerca do espaço por meio do entendimento de diversas dinâmicas.

O ambiente escolar produz muito no que se refere à formação dos sujeitos, pois nele aprende-se a conviver com as diferenças - de modo a respeitálas e a potencializar tudo aquilo que elas podem oferecer. Ainda, é o ambiente em que ocorre a troca de conhecimentos, devido a isso deve procurar abranger a todos sem que haja qualquer tipo de 
descriminação, inclusive aquela causada pela falta de conhecimento e domínio técnico.

\section{Encerramento}

As grandes transformações ocorridas no ensino da Geografia motivadas pela passagem do modo tradicional de ensino para uma abordagem crítica, desenvolveram um novo olhar sobre a disciplina. A importância de proporcionar novos modos de ler e pensar o mundo em que vivem os alunos, juntamente com os objetivos da disciplina, possibilitaram a geografia investir na formação de sujeitos capazes de fazer novas leituras acerca de suas realidades.

Pensar o ensino de Geografia para alunos surdos não deve ser diferente. Partindo do pressuposto de que a disciplina possuí conhecimentos básicos e uma linguagem própria, a qual os sujeitos devem dominar para serem capazes de articular as diversas realidades, deve-se proporcionar, por meio da Libras os mesmos conhecimentos. Necessita-se, para isto, que os professores tenham o domínio da Língua Brasileira de Sinais e que a operem no campo das dinâmicas geográficas.

A linguagem e a comunicação são fundamentais no processo de aquisição dos conhecimentos geográficos e para que os alunos surdos tenham acesso à possibilidade de refletir e aplicar em suas vidas os conteúdos desta disciplina, de forma satisfatória. Assim, a partir da linguagem geográfica, apresentada por meio da Libras, os alunos surdos poderão ler o espaço, criando conexões sociais e culturais, aprendendo sobre valores, normas e regras e vida em comunidade.

\section{Referências}

ARAUJO, Danielle Mirelli da Silva; SILVA, Marcelle de Castro; SOUZA, Wilma Pastor de Andrade. A influência da libras no processo educacional de estudantes surdos em escola regular. 2007. Trabalho de Conclusão de Curso (Graduação em Pedagogia) - Universidade Federal de Pernambuco, Recife.
BRASIL. Lei Federal n. 10.436 de 24 de abril de 2002. Dispõe sobre a Língua Brasileira de Sinais Libras e dá outras providências. Disponível em: <http://www.planalto.gov.br/ccivil_03/Leis/2002/L 10436. htm>. Acesso em: 08 de set de 2016.

BRITO, Franklyn B; PESSOA, Rodrigo B. Da origem da geografia crítica a geografia crítica escolar. $10^{\circ}$ Encontro Nacional de Prática de ensino em Geografia. Porto Alegre, 2009.

CALLAI, Helena Copetti. Do ensinar geografia ao produzir o pensamento geográfico (p. 57-73). In: REGO, Nelson (org.) et al. Um pouco do mundo cabe nas mãos: geografizando em Educação o local e o global. Porto Alegre: Ed. da UFRGS, 2003.

CALLAI, Helena Copetti; ZARTH, Paulo A. O estudo do município e o ensino de história e geografia. ljuí: Ed. Unijuí, 1988.

CAVALCANTI, Lana de Souza. Geografia e prática de ensino. Goiânia: Alternativa, 2002.

CAVALCANTI, Lana de Souza. Geografia, escola e construção de conhecimentos. $7^{a}$ ed. Campinas, SP: Papirus, 2005.

DARSIE, Camilo. Educação, geografia e saúde: geobiopolíticas nos discursos da organização mundial da saúde e a produção da mundialidade pelo controle de doenças. 2014. 234 f. Tese (Doutorado em Educação). Faculdade de Educação - Universidade Federal do Rio Grande do Sul, Porto Alegre.

DEUS, Maria L. F. Surdez: linguagem, comunicação e aprendizado do aluno com surdez na sala de aula comum. 2012; Monografia; (Aperfeiçoamento/Especialização em Atendimento Educacional Especializado) Universidade Estadual de Maringá, Maringá.

GESUELI, Zilda Maria. Lingua(gem) e Identidade: A surdez em Questão. Revista Educação e Sociedade, Campinas, v. 27, n. 94, p. 277-292, jan./abr. 2006

MASSEY, Doreen. Pelo Espaço: uma nova política da espacialidade. Tradução de Rogério Haesbaert e Hilda Preto Maciel. Rio de Janeiro: Bertrand Brasil, 2009

MINUZZI, Crislaine; FACHIN, Paulo Cesar. Estudo Sobre Língua e Linguagem: considerações. Disponível em: <http://www.educadores.diaadia.pr.gov.br/arquiv os/File/marco2012/portugues_artigos/linguagem. pdf.>. Acesso em: 14 set. 2016.

MOURA, Rosa; OLIVEIRA, Deuseles de; LISBOA, Helena dos Santos; FONTOURA, Leandro Martins, GERALDI, Juliano. Geografia Crítica: legado histórico ou abordagem recorrente?. 
Revista Bibliográfica de Geografía y Ciencias Sociales. Barcelona, v. 13, n. 786, jun. 2008.

NASI, Lara. O conceito de língua: um contraponto entre a Gramática Normativa e a Linguística. Revista Urutágua. Maringá, n. 13, ago./nov. 2007.

PERINI, Mário A. Sobre língua, linguagem e linguística: uma entrevista com Mário A. Perini. Revista Virtual de Estudos da Linguagem REVEL. v. 8, n. 14, 2010.

PESSOA, Rodrigo Bezerra. Um olhar sobre a trajetória da geografia escolar no Brasil e a visão dos alunos de ensino médio sobre a geografia atual. 2007. 130 f. Dissertação (Mestrado em Geografia) - Centro de Ciências Exatas e da Natureza, Universidade Federal da Paraíba, João Pessoa.

QUADROS, Ronice M de; KARNOPP, Lodenir. Lingua de sinais Brasileira: estudos linguísticos. Artmed: Porto Alegre, 2004.

RIBEIRO, Márcio Willyans. Origens da disciplina de Geografia na Europa e seu desenvolvimento no Brasil. Revista Diálogo Educacional, Curitiba, v. 11, n. 34, p. 817-834, set./dez. 2011

ROSA, Danielli Gomes. Educação e surdez - em defesa da língua de sinais para a inclusão social dos surdos. 2013. 53 f. Trabalho de Conclusão de Curso (Graduação) - Curso de Pedagogia, Universidade Federal do Estado do Rio de Janeiro, Rio de Janeiro.
SANTOS, Milton. Espaço e Sociedade. Petrópolis: Vozes, 1979.

SCHULZ, Lisiane O; CUSTODIO, Magda M. C; VIAPIANA, Simone. Concepções de Língua, linguagem, ensino e aprendizagem e suas repercussões na sala de aula de língua estrangeira. Revista Pensar Línguas Estrangeiras, Caxias do Sul, n. 1, mar./set. 2012.

TELES, T. A. F. . linguagem e identidade social - uma abordagem 2005. (Apresentação de Trabalho/Comunicação).

VLACH, Vânia R. F. A propósito do ensino de Geografia em questão o nacionalismo patriótico. 1988. 206p. Dissertação (Mestrado em Geografia) - Universidade Federal de São Paulo, São Paulo. 